\title{
The Development of the Associative Movement in Morocco: Challenges and Constraints
}

\author{
Mohamed Ait Oujaa \\ Doctorate Candidate, Mohammed V University, Rabat
}

\author{
Doi:10.5901/mjss.2015.v6n3p415
}

\begin{abstract}
The present article has for aim to address the disequilibrium and fragmentation from which Moroccan associations suffer as well as to direct the attention towards the different challenges and constraints which the associative movement in Morocco has confronted and which have contributed in this latter's evolvement regardless of the encountered difficulties. First and for most, this article will review the main historic periods tracing the existence of associative movements in Morocco while focusing on the significant challenges and constraints having been confronted by these latter. Second, while the main purpose of this articles is to analyze and explain these challenges and constraints and at the same time looking into the role which they have played in establishing the situation, this paper will also address the many interrelated factors which have led to this disequilibrium and the promotion of chaos in the network of associations most of which are considered related to human behavior, that is, the behavior of actors in the network of associations, while others are related to non-human actors. Finally, the article will conclude that the socio-economic and political evolution of the country agrees with adopting an associative approach even though it is a slow and laborious process.
\end{abstract}

Keywords: Morocco, Associative Movement, Challenge, Constraint, Civil Society.

\section{Introduction}

Over the recent years, the non-profit institutions' sector (NPIs), commonly known as 'civil society' or 'associative movement', has developed considerably. Through its proximity to the population and its commitment to the needs and interests of the citizens in various fields (economic, educational, social, cultural, infrastructure, religious, etc.), the associative movement has become an essential component of the economic and social life of the country. The synergies which it develops with public authorities and the private sector through partnership agreements have further strengthened its role and contributed to its development.

Morocco is also witnessing a new form of an international civil society to which the profit is not the main objective. It is rather in this context that new forms of economy and solidarity emerge allowing us to speak of a solidarity economy ${ }^{1}$. In this context, the role of an ideal civil society would be to make three sectors cooperate together: the State, the private sector, and the nonprofit sector with a social vocation.

Given this inescapable fact, the investigation which we undertake, to date, has as its foundation the finding that the associative movement in Morocco is facing enormous challenges and constraints due to the level of the human resource competence at the level of socially- motivated institutions and the near absence of appropriate materials made available to these latter.

\section{Objectives and Methodology of the Study}

\subsection{Objectives of the Study}

The purpose of the present study is to provide a theoretical overview on the evolution of the Moroccan associative movement as well as the various constraints and challenges it confronts. First, the paper aims to define the different steps through which the associative movement has gone, the manifestations of its development as well as its

\footnotetext{
1 "The solidarity economy can be defined as the set of activities which contribute to the democratization of the economy through the contribution of citizens. Far from substituting the State's actions, Solidarity economy seeks a joint with it, a re-investment in the economy as a social and cultural integration project "(Laville, 2001: 21). The concepts of "solidarity economy" and "solidarity axes associations" lead us to draw a parallel with the concept of "the gift" as it was proposed by Mauss (1989) and compare it with the concept of "the gift" (and of the "anti-economic") in Arab-Muslim societies (Benabdelali, 1999).
} 
controversial relationship with the State. Another objective of this article is to underline the challenges and constraints to its development.

\subsection{Methodology}

To achieve the above objectives, a thorough review of the existent literature is used as a technique to explore the challenges and constraints linked to the development of the Moroccan Civil Society. This literature review is a technical assessment of the existing research on the subject of the study. The main objective of the review is to provide, evaluate, analyze and synthesize knowledge and ideas shared by other studies on the problem, the purpose of which is to have the necessary foundations to complete our research with the qualitative study (i.e. the questionnaire) which will be the subject of our next article.

\section{Genesis of the Moroccan Associative Action}

The associative action, in the modern sense of the term, is a recent phenomenon in Morocco. It has been introduced with the protectorate at the beginning of last century. Certainly, we cannot deny ${ }^{2}$ that Morocco, through its history, has, beforehand, experienced other institutional forms ${ }^{3}$, from its traditions which were, one way or another, of associative aspects such as the guild 4 . However, it would be absurd, if not an exaggeration to say that the youth of the associative movement constituted a focus for these traditional institutions. On the contrary, it turns out that the young found difficulties to access these social institutions.

The associative work in Morocco, in its regulatory and institutional form, dates back to the early years of the installation of the French protectorate. It is in the areas of youth, sports, charitable and pious sectors that the first associations are structured. Their common feature actually met the characteristics of this period of the protectorate, namely the assertion of their Moroccanity, the attachment to their identity and the implementation of the Moroccan heritage.

In 1932, an association called "Union Sportive de Rabat-Salé" (henceforth USRS) was created (Mernissi, 2008). It constituted the real launch of a Moroccan youth associative movement.

Upon the country's independence and particularly after the promulgation of the Dahir of 1958 on civil liberties, associative action began to assert itself.

We usually talk about four generations of associations which correspond to four major periods in the history of Morocco. These have all begun after independence, although the years under French and Spanish protectorate witnessed the creation of several associations working in the fields of culture, education, scouting, sports and social action.

The first period, which extends approximately from 1956 to 1975, is characterized by the creation of associations specifically Moroccan in a climate of relative freedom. Thus, several associations specialized in the field of children, youth and sports were created over the years.

At that time, young people became more aware of the role they should play in their liberated country. Their role had materialized in several economic and social projects: reforestation, school operation, and fight against illiteracy, which are examples of responsibility and involvement of young people in the construction and implementation of the development of the country, such as the participation of 12000 young people in 1957 in the construction of the Road of Unity (Al Wahda).

The second period, between 1975 and 1984, saw the largest mobilization of Moroccan youth under the Green March (1975). 75\% of the marchers were under 25 years old (Ikken, 1999). Thus, a clear regression of the exercise of freedom of association was linked to the limitation of freedoms in general. Despite this, the associations have played an important role in social, culture and sport activities in the country. It was at this time that the first associations of human rights, women's groups and child protection associations were created; the Moroccan Association for Human Rights $(\mathrm{AMDH})^{5}$ was created in 1975, the Moroccan Organization for Human Rights $(\mathrm{OMDH})^{6}$ in 1978, and the Moroccan

\footnotetext{
2 For more details on the lack of the associative culture in Morocco, see Denoeux \& Gateau, (1995)

${ }^{3}$ Before the Protectorate, socio-economic relations were organized as an association, whenever it was a question of combining the joint effort of individuals from homogeneous social groups to overcome the difficulties of all kinds of community life (Ameur \& Filali Belhaj, 1997: 5).

${ }^{4}$ The guild is the name given to a "regulatory" grouping of artisans, at the head of each business grouping is a leader named 'Lamine'.

${ }^{5}$ Association Marocaine des Droits de l'Homme

${ }^{6}$ Organisation Marocaine des Droits de l'Homme
} 
League for Human Rights (LMDH)7 in 1979 (Faouzi, 2007).

But during this period, with the exception of those working in the field of human rights, existing associations were neither seen as an expression of the aspirations of the civil society nor as spaces of the participation and maturation of citizens being able to be involved in the process of political, economic, cultural, sporting, and social democratization.

The third period extends from 1985 to 1994. It took until the late 80s to attend a new direction in the development of the Moroccan associations. Under the impact of the international context ( Morocco entered into a deficit phase due to the application of the Structural Adjustment Program (PAS ${ }^{8}$ ) (Maroc Possible, 2006)) and the changes which have occurred at the internal level, the associations began to be perceived as essential partners in the redevelopment process of economic and social balance of the country. Henceforth, we are witnessing an expansion of associations and the establishment of new associative vocations which do not seek to provide services but rather to mobilize citizens as partners of the government in the selection and implementation of development.

Meanwhile, the current period began in the mid 90s and corresponds to an effective assertion of Moroccan associations. Thus, from 1995 appeared a new type of association, such as Afak, Alternative, and Maroc 2020. Also, the first environmental protection associations have emerged side by side with the complexity of the social fabric by the emergence of several professional associations, Health, STD / AIDS, neighborhood consumption, users, foundations (Mohammed V Foundation for Solidarity, Mohammed VI Foundation for the reintegration of prisoners). This type of associations seeks to promote the values of civic responsibility and constructive citizenship for a modern society. Their actions were intended for a wide distribution to the public and the media were widely used to convey their messages.

Nowadays, Moroccan associations have experienced a dramatic boost. In 2014, the number of actually active associations is estimated at more than 60,000 organizations, namely 185 per 100,000 against 17,000 associations in 1997. Nonetheless, it remains below the average; for example, 1749 in France in 2005, and 508 in Canada in 2003. Many of these associations are active in a local frame at a locality or a neighborhood levels.

\section{Challenges of Associative Work}

Despite its young age, the Moroccan NGO sector plays an important role in strengthening the Moroccan civil society, the establishment of the rule of law and the effective participation in the process of local development. Indeed, if, for some analysts, the opening on the issues of human rights, citizenship and good governance is largely due to the positive effects of new international circumstances, it is recognized that it is as much the substantive work of the association members as that of the emergence of an inconvenient but still growing civil society which was at the basis for this change. All in all, it remains bearer of change and hope as not only citizens but also the government show interest in it.

Moreover, several aspects and decisive factors make that the effective operational capacity of civil society remains below the potential it holds because of several inconsistencies ranging from the loss of identity to the total confusion of roles it plays.

\subsection{A young NGO sector in a consolidation phase requiring an unconditional support to enable the building of a strong civil society (in particular):}

The number of local associations which continues to grow every year, therefore, requires a great effort for their supervision. For instance, more than 3,000 local associations are operating in the North of Morocco. Thus, despite the efforts made during the last four years, the NORTHERN NGOs Forum has been able to support only a hundred associations; which is an indicator of the coaching needs of local associations. The establishment of local associative dynamics undoubtedly meets the expectations of these associations.

\subsection{The weakness in the institutional and organizational capacity of associations:}

Most associations have a simplistic yet limited view of their role in the process of local development. Their reduced competences, both human and financial, do neither allow these associations to ensure strategic planning of their intervention nor to be assertive as major operators of economic and social development. Hence, there is a lack of organizations which can insure the defense of the most vulnerable groups including women's organizations and those dealing with the problems of the disabled, children, etc.

\footnotetext{
${ }^{7}$ Ligue Marocaine des Droits de l'Homme

8 Programme d'Ajustement Structurel
} 


\subsection{An unfavorable partnership environment to the development of associative work:}

Despite the very diverse partnership relations developed by Moroccan associations in the recent years, reports to the authorities remain very informal because of the difficulties in institutionalizing entrepreneurial relationships with communities and local governments.

Indeed, one of the directions which NGOs are trying to develop has to do with the strengthening of partnership policies and the exchange inter NGOs towards a better capitalization of resources, an increased valorization of the knowhow and an optimization of a consultation and coordination to guarantee an efficient contribution of the associations as key players in the local development. The goal is to foster a sustainable development policy in which the associations have the required authority to occupy the spaces which belong to these latter and which stakeholders will grant them.

In this context, the establishment of the local consultation and coordination structures will have a key role to play in order to participate in the promotion of the local governance and occupy the spaces of influence which can strengthen associative representativeness and its legitimacy which is recognized as a key player in the inescapable management of public affairs in Morocco.

\subsection{The role of civil society below the local populations' expectations}

In Morocco, in the opinion of many experts, the favorable conditions for an active participation in the emergence of good governance are not yet acquired. The social dimensions are lacking in most development programs advocated by the government. This manifests itself, increasingly, through systematic questioning of the structures, the processes and the institutions around which society organizes and decides the criteria of power management, the allocation of public resources, and the arbitration between different individual and group interests.

\subsection{Volunteering and professionalism in associations}

Inspired by the intent of the 1901 Act with respect to associations in France, the Moroccan Parliament states "'the association is the convention by which two or more persons pool, permanently, their knowledge and activities for a purpose other than profit sharing". 9

This definition implies mutual recognition of rights and duties for all partners, the pursuit of a common goal (Professional, scientific, cultural, socio-economic, legal and humanitarian, sports ...), the joint implementation of the knowledge and the means, as well as a no-search for profit or gain. Therefore, acts of membership in an association are a legal, sovereign and responsible act.

Adhering means active and responsible participation in the work and activities of the association in view of the fulfillment of a given object: targeted operations, installation of a program of action, opening of training sites or workshops, etc.

The effectiveness of the work in association presupposes the establishment of communication between all stakeholders -decision makers and project managers-, an equal treatment to information and decision-making. It depends, too, on the ability of each member to engage in an activity in which they could implement their skills and even thrive. The distribution of competences, from this angle, is a necessary thing, because it affects the rest of the project, according to the rule which puts "the right man at the right place".

Also, the roles which the associate partners have to play presuppose they have a clear and consistent vision of the responsibilities, tasks and activities. It is imperative, thereby, to separate the overall strategy (design and orientation) of the act of ensuing decision and implementation tasks. The strategy and the decision shall be performed by a management structure, while the initiation of programs and actions is provided by volunteers or employees, working under the direct responsibility of an executive manager, project or operation manager. This latter may be part of the management structure as he can be appealed from the outside and be remunerated accordingly. In this case, in use in structured associations, he does not enjoy any elective responsibility within the association. His powers and his relations with the elected leaders must be stipulated in writing, either in the rules of procedure or in a separate but attached document.

These are some signs which should govern the proper functioning of an association, aspiring to efficiency and professional standing. The aspirant, although legitimate, raises the issue of professionalism of the service, with its immediate corollaries, relevance volunteer, internal democracy and resource empowerment.

${ }^{9}$ Article I of the Royal Decree of 15 November 1958 regulating the right of associations in Morocco. 
Surely, if Moroccan associations have operated hitherto in a random fashion, under the cover of volunteering and volunteerism, the limitations of such an approach are apparent since many projects could not succeed and that actions taken, even if they are successful, do not guarantee the sustainability of the associative structure, which is the instigator of such actions. The associations which were able to maintain and consolidate their gains are those which benefited from the logistical and financial support of national and international organizations. This partnership has allowed, in addition, these associations to create basic structures to better manage themselves and further refine internal mechanisms in respect of the delegation of responsibilities and program monitoring.

The exercise of volunteering, whether it is desirable in the short term, in the case of the associations which start or address a niche for which they are not equipped, is detrimental to the medium and long terms. Volunteering creates the problem of the availability of volunteer actor: it is obvious that we cannot ignore the work and family commitments of this latter and which at the risk may hinder activities monitoring since it is difficult to demand accountability from a volunteer who has not completed his/her task well. In addition, voluntary or charitable work creates the problem of the formation of candidates and the desired skills. Participants in associative work must master the techniques and acquire the required capacities to exercise their new responsibilities. This mastery can be achieved, however, by the ongoing work on the field and through appropriate training sessions.

In addition, international institutions specialized in the financing prefer to negotiate with the associations which are endowed with adequate structures at both the managerial and functional levels, that is to say, which have a powerful permanent structure to guarantee the smooth running of finalization and project implementation. Also, should projects funding parameters depend on the institutional and professional capacity of the applicant association; because, ultimately, the equation, without being simple, is of an unwavering rigor: the financing of a project presupposes the existence of reliable skills involving ipso facto a professionalizing process which can achieve the desired objectives. This innovative approach is not without causing critical questions about the future of many associations.

In this context, the issue of professionalism is acute. It appears that in the current state of the associative experience the notion of professionalism is formulated closely with project funding. Instead of being designed and thought as a serious alternative to the ambient amateurism, professionalism is perceived by the associative partners as a precondition demanded by international donors.

In fact, the development of the voluntary sector depends, to a large extent, on its ability to become more professional at all stages of its operation and its approach, despite the financial constraint ${ }^{10}$. Associations must, at first, form a network, horizontally (spatial clustering at the level of the municipality, prefecture, province and region), vertically (grouped by specialty or area of activity) and transversely (networking around a multi-thematic pole or around international agencies, donors). Once established, these networks - as is the case of Associative Space - can exert lobbying on public authorities to close judicial loopholes which hinder associative action and ensure technical support of specialist services of the state. At this domestic level, this time, the scale of involved structures will push partners to pave the way for a professional start in terms of managerial management, marketing, internal democracy, financing, relations with the various components of the associative structure (dyads officials / permanent, permanent / volunteers, founders / active members ...), relationships, partnering or conflicting, with competing associations, etc.

Therefore, it is imperative for the sector to develop a clear design, and strategically powerful, professional associations, which exclude in any way the inspired spirit of volunteering, provided they are supervised by professionals and oriented to the execution of targeted tasks. Volunteering constitutes, above all, the first and undeniable basis of associative action. In this perspective, organizing regular training sessions for executives, permanent and non-permanent in the area of the development, management and completion of projects, can only contribute to a better understanding between the players, able to promote the desired synergies and planned interactions, for, in the end, a good structure is a structure which works well, without failure, and whose members are permanently part of the action they initiate, convinced of its relevance and viability means which are mobilized in it.

To conclude on this point, it is certain that the associative action can only develop sustainably by professionalizing and regrouping. This professionalization goes, first, through the efficient management of volunteering, resource management (human and material), then necessary technicality for the design, conduct and completion of projects.

\section{The Constraints Linked to the Development of the Associative Movement}

Despite the existence of a large number of associations in Morocco and their significant potential to mobilize civil society,

10 In France, the number of associations is estimated at more than 700,000 and the number of adherent at 20 million. There would be 1,250,000 employees; 800,000 full-time employees equivalent to 120,000 associations. 
the actual associations active in the field of local development are few. The absence of a legal framework conducive to the involvement of associations in the social development process, the lack of structure and materials and human resources are obstacles impeding associative work.

\subsection{The legal constraints}

In Morocco, the immobility of association law has condemned the associations to operate within limits particularly in terms of ownership and administration of property and voluntary heritage.

\subsubsection{Legal personality}

Legal personality available to Moroccan associations is very limited. The recognition of the public interest is reflected in the strengthening of the legal capacity of associations of public utility so-called "of great personalities" by allowing them to benefit from additional resources to finance their activities, which is not the case for declared associations, say "of small personalities", only benefiting from enumerated and limited subsidies by the legal text.

Better yet, this personality is even more limited due to the absence of a case law interpreting the general terms of the law to provide the Moroccan associations necessary attributes to the modern concept of the association enterprise.

\subsubsection{Legal capacity}

In Morocco, contrary to what happens in other countries, the courts do not participate in the expansion of the legal capacity of associations by a favorable interpretation of the texts. In France, for example, case law allows associations to engage in trade and to be self-financing by means other than those prescribed by law as any other enterprise.

\subsubsection{Patrimonial right}

Legally, unreported public utility associations do not have the heritage capacity. Again, this is an obstacle to the development of associations which require significant material resources. These associations can only own the buildings strictly necessary to the exercise of their activities and to the achievement of their objectives, which is not the case for associations with the public interest to which the law grants more expanded movable and immovable property rights.

"This is how more than half of the associations have no room to operate. For the rest, $29.6 \%$ are hosted for free (mainly by public or private institutions in $58 \%$ of the cases or in the home of one of the members in $29 \%$ of cases), $11 \%$ are tenants and $8.4 \%$ own their premises" (HCP, 2011).

Finally, we can say that the financial and asset limits from which Moroccan associations suffer further constrain their scope and, consequently, negatively impact their ambitions.

Many obstacles make associative work difficult as well as every possibility of developing a financial autonomy. What about institutional deficits?

\subsection{The institutional constraints}

In addition to the legal limits, other constraints make associative work in Morocco difficult. It is question of organizational obstacles relating to association management and the structuring of associations, not to mention the low practice of partnership either between associations themselves or between them and the State.

\subsubsection{Deficit in terms of partnership}

\subsubsection{Between associations and public authorities}

So that the mobilization potential of civil society acts as a regulator lever, it is required that the government apparatus and local communities open up to a culture of partnership with associations.

It is true that the government declaration of April 1998 erected the associations as potential partners could play an important role in regional and local development, but it is a lure to legitimize and validate policies without considering the 
issued opinions of the associations.

Generally, municipalities remain very septic against particular associations which, unlike the State, come to approach very closely the most vulnerable and marginalized layers. Urban or rural local officials do not want competing actors and consequently, systematically oppose any attempt to open on social actors despite their dynamism and vigor. Contrary to what is the partnership between municipalities and associations, working with NGOs is less confrontational in that they provide knowledge and often significant material resources to enhance the action of the concerned local communities.

\subsubsection{Lack of communication network between associations}

Networking is a quite recent practice. Sectors which have known it are mainly the economic and financial fields, while the cultural and social fields are minimally affected by the movement. Indeed, several networking attempts have been considered but so far this has been much more formal than operational. Associations continue to work in a dispersed manner: each association cares very little about the actions taken by others. Only $7.9 \%$ of the associations have established partnerships with the State or public establishments, $2.7 \%$ with local communities and only $1.5 \%$ have worked in a partnership framework with Foreign Countries. (HCP, 2011)

The networking of the associations has for aim to strengthen the work of associations and the network without this one substitutes for its components. It is also a framework for coordination, guidance and information.

The legal text governing the networks is the same as the one governing associations. However, the risk is a reproduction of the same logic of the wait, the hierarchy and the leadership.

\subsubsection{Deficit at the organizational level}

\subsubsection{The status of social workers}

The Moroccan NGO sector does not benefit from a social security cover for lack of funds. Although it is a generator of wealth for the country, its social workers are not recognized in terms of social security.

\subsubsection{The absence of strategy and clear mission}

The associative action suffers from an absence of global vision in the medium and long term and from a development policy. Thus, the definition of a clear orientation, of priorities and their translation into goals, mobilization of human and material resources and their management are obstacles for the majority of Moroccan associations.

All of these factors lead to a problem of identity, mission and values. In wanting to respond to all requests, associations operate in a dispersed manner or even inefficiently.

\subsubsection{Association management and lack of professionalism}

Volunteering, although it is an asset, is an obstacle to development for the organization and the management of an association. This being said, the volunteers are not the best equipped to manage the projects of the association; they have neither the competence nor the availability to ensure the smooth running of an association. In addition, the insufficiency of the executives' professionalization is likely to limit the ability of these latter to properly diagnose problems, formulate plans and implement them.

Also, the founders of associations, personalizing power, sometimes tend to use the association for commercial or personal use purposes. In most cases, they are part of departments which want to incorporate within their associations the bureaucratic and hierarchical "Ministry Culture", which is completely incompatible with the local approach on which any association should be based. Thus, a reflection should be conducted in this direction when thinking the organization of the voluntary sector.

\section{Conclusion}

If everyone agrees on the fact that economic and social development cannot be contemplated without the active participation of civil society, and that the role of the association is now the backbone of any reform, it will be necessary to admit the existence of a disability of associations to remain in line with the general guidelines of the State and be at the 
level of social challenge.

Internally, organizations face the same fragmentation which affects the political class. They act in a disorganized fashion and have a hard time encouraging a dynamic grouping or networking, only able to enhance their work and the expected impact.

Functionally, the associations are characterized by a structural deficit in management, marketing, communication and partnership.

Only associations sustainably supported by international NGOs are beginning to restructure correctly. The access to information technology and the progressive and irreversible opening of Morocco on the outside as well as the political will which aims to improve the social action (national initiative for social development) will favorably influence the associations.

The country's political and socio-economic development goes in the consolidation of an associative approach. It is question of a slow but laborious process.

\section{References}

Ameur, M. \& Filali Belhaj, A. (1997). Développement urbain et dynamiques associatives, ANHI, Rabat.

Benabdelali, N. (1999). Le Don et l'anti-économique dans la société arabo- musulmane, Eddif, Casablanca.

Bourqia, R. (1995). Jeunesse estudiantine marocaine Valeurs et stratégies, Publications de la Faculté des Lettres et des sciences Humaines de Rabat, $127 \mathrm{p}$.

Denoeux, G. \& Gateau, L. (1995). «L'essor des associations au Maroc : à la recherche de la citoyenneté ? ». Revue Maghreb Machreck, $\mathrm{N}^{\circ} 150$.

Faouzi, M. (2007). « Genèse de l'action associative marocaine », Le matin 28/03/2007

Fondation IPADE. Associations et organisations non gouvernementales au nord du Maroc : l'articulation de la societé civile dans les provinces de Tanger, Tétouan, Chefchaouen et al Hoceima, Lopez Eva, Retrieved from: http://www.iecah.org/web/images/ stories/publicaciones/libros/descargas/Resume_executif_etude_societe_civile_Nord.pdf

Hall, M.H, et al (2003). Force vitale de la collectivité : Faits saillants de l'enquête auprès des organisations à but non lucratif et bénévoles ». Statistique Canada.

Ikken, A. (1999). Les organisations de jeunesse au Maroc, AL ASAS, $151 \mathrm{p}$.

LaVille, J. (1997). Sociologie de l'association.. Desclée de Brouwer,Paris. Le Cahiers de I'Orient, n. 58 -2000, "Le Maroc de Hassan II".

Le Haut Commissariat au Plan, (2011). Enquête nationale auprès des Institutions San But Lucratif (ISBL)

Le Maroc Possible, collectif. (2006). « Rapport du Cinquantenaire ». 288 p.

Mauss, M. (1989) "Essai sur le don. Forme et raison de l'échange dans les sociétés archaïques" in Sociologie et anthropologie, PUF : Paris.

Mernissi, F. (2008) A quoi rêvent les jeunes, MARSAM, 190p.

Salaheddine, A. (2014). «Maroc: 2 milliards de dirhams débloqués aux associations». Aujourdhui.ma, 19-

Tchernonog, V. (2007). « Les associations en France : Poids, profils et évolutions -novembre 2007- ». CNRS 'Centre d'Economie de la Sorbonne. 